\title{
POST-TRIAL ACCESS TO ANTIRETROVIRALS: WHO OWES WHAT TO WHOM?
}

\author{
JOSEPH MILLUM
}

\section{Keywords}

HIVIAIDS,

antiretrovirals,

ART,

post-trial access

\begin{abstract}
Many recent articles argue that participants who seroconvert during HIV prevention trials deserve treatment when they develop AIDS, and there is a general consensus that the participants in HIVIAIDS treatment trials should have continuing post-trial access. As a result, the primary concern of many ethicists and activists has shifted from justifying an obligation to treat trial participants, to working out mechanisms through which treatment could be provided. In this paper I argue that this shift frequently conceals an important assumption: that if there is an obligation to supply treatment, then any party who could provide it may be prevailed upon to discharge the obligation. This assumption is false. The reasons why trial participants should get $A R T$ affect who has the duty to provide it. We should not burden governments with the obligations of sponsors, nor researchers with the obligations of the international community. And we should not deprive a group of treatment because their need is less salient than that of research participants. Insisting otherwise may lead to people being wrongfully deprived of access to antiretrovirals.
\end{abstract}

\section{A. THE PROBLEM}

\section{Introduction}

Everyone agrees that people with AIDS deserve to be treated. Unfortunately, despite a recent flood of resources to combat HIV/AIDS in the developing world, not everyone who needs treatment gets it. In December 2007, of the 9.7 million people in urgent need of treatment for HIV/ AIDS in low- and middle-income countries, only about 3 million of them received it. ${ }^{1}$ Until antiretroviral therapy is universally available, difficult decisions must be made

\footnotetext{
1 AVERT. 2008. AIDS Treatment Targets and Results: All by 2010. Available at: http://www.avert.org/aidstarget.htm [Accessed 26 Jan 2009].
}

about how to direct limited resources, and strategies must be found to increase them.

Participants in HIV/AIDS research comprise one group that might have a special claim to antiretroviral therapy (ART). In a slew of recent articles it has been argued that participants who seroconvert during HIV prevention trials deserve treatment when they develop AIDS, ${ }^{2}$ and there is a general consensus that the participants in HIV/AIDS treatment trials should have

\footnotetext{
${ }^{2}$ E.g. B. Lo, N. Padian \& M. Barnes. The Obligation to Provide Antiretroviral Treatment in HIV Prevention Trials. AIDS 2007; 21: 1229 1231; R. Macklin. Changing the Presumption: Providing ART to Vaccine Research Participants. AJOB 2006; 6(1): W1-W5; U. Schüklenk \& R. Ashcroft. International Research Ethics. Bioethics 2000; 14: 158-172.
}

Address for correspondence: Joseph Millum, Clinical Center Department of Bioethics/Fogarty International Center, Building 10, Room 1C118, NIH Clinical Center, National Institutes of Health, Bethesda, MD U.S.A. 20892. Phone: +1 301594 5519; Fax: +1 301 496 0760; email: millumj@cc.nih.gov 
continuing post-trial access. ${ }^{3}$ As a result, the primary concern of many ethicists and activists has shifted from justifying an obligation to treat trial participants, to working out mechanisms through which treatment could be provided.

In this paper I argue that this shift often conceals an important assumption: that if there is an obligation to supply treatment, then any party who could provide it may be prevailed upon to discharge the obligation. This assumption is false. I enumerate the different justifications that have been proposed for an obligation to provide ART to HIV/AIDS trial participants and show what, if sound, each would justify. ${ }^{4}$ In general, I conclude, justifications that would place the onus on government programs imply that the governments would have similar obligations to people outside of medical research. They are unlikely to justify simply shifting resources from non-participants to participants. On the other hand, justifications that would imply an obligation owed just to research participants tend to be those that obligate just the researchers and their sponsors. Were these duties substantial enough to include the provision of ART, they would require increasing the total resources directed to HIV/AIDS treatment. Awareness of these implications should encourage more critical reflection on exactly who has obligations to supply treatment and to whom they are obligated. Ignoring them risks unjustly depriving some people of treatment to which they are entitled.

\section{Treatment and prevention}

For the most part, HIV/AIDS treatment trials test antiretroviral drugs, drug regimens, and mechanisms to improve adherence to these regimens. Prevention trials are more variable: they may test behavioral interventions, vaccines, microbicides, surgical interventions, and so on. Since AIDS is currently incurable, participants in HIV/AIDS treatment trials leave the trial still needing

\footnotetext{
${ }^{3}$ See, e.g. The Nuffield Council on Bioethics. 2002. The Ethics of Research Related to Health Care in Developing Countries. London: Nuffield Council on Bioethics: 120-121; World Medical Association. 2008. Declaration of Helsinki: Ethical Principles for Medical Research Involving Human Subjects: Paragraph 33.

${ }^{4}$ Assessment of the soundness of these arguments has been attempted elsewhere, and so, for the most part, I do not replicate it here. For some comprehensive critical evaluations see C. Slack et al. Provision of HIV Treatment in HIV Prevention Trials: A Developing Country Perspective. Soc Sci Med 2005; 60: 1197-1208; C. Weijer \& G.J. LeBlanc. The Balm of Gilead: Is the Provision of Treatment to those Who Seroconvert in HIV Prevention Trials a Matter of Moral Obligation or Moral Negotiation? J Law Med Ethics Winter 2006: 793-808. I note other critical work as I consider particular arguments.
}

treatment. And at the end of a successful HIV prevention trial, some participants are likely to have contracted HIV: late-phase prevention trials typically rely on showing a difference in infections between experimental and comparison arms to show that an experimental intervention is effective. Thus, trials of both types will conclude with participants who need, or will need, treatment.

It is worth noting two of the key differences between treatment and prevention trials that can be relevant to the arguments made in favor of post-trial treatment for participants. First and foremost, the study population for treatment trials starts the trial infected, and the study population for prevention trials starts uninfected. This has implications, for example, concerning what sorts of harms can be caused by trial participation and so what sorts of injuries researchers and sponsors could be responsible for. Second, in treatment trials all the participants need treatment directly following the trial, but following prevention trials there is generally a substantial time-lag before those who seroconvert require treatment. This presents additional practical difficulties in discharging an obligation to provide ART. ${ }^{5}$ Despite these differences, however, arguments citing the same moral factors have been or could be developed for both treatment and prevention trials in order to justify an obligation to supply infected participants with posttrial access to ART. Hence, for the most part I deal simultaneously with arguments for post-trial access for participants in both trial types. I note along the way where the differences between them make a moral difference.

In both cases this paper focuses on the extent of the obligation to supply ART to trial participants who need it, where supplying ART includes paying for antiretroviral drugs, but also providing or supporting the medical personnel and other resources that are needed to actually deliver them. There are, of course, other ways in which people suffering from HIV/AIDS may need help, and so other possible obligations of care to trial participants. These include counseling, treatment of opportunistic infections, monitoring of patients' health status, assistance with accessing medical care elsewhere, and so forth. I focus on supplying ART because it has become the focal issue for the debate over obligations of care to HIV/AIDS trial participants. However, as I note in the conclusion, my arguments apply equally well to other forms of care and other care might be necessary or sufficient for the discharge of certain obligations.

\footnotetext{
${ }^{5}$ See Section 3.
} 


\section{How might ART be supplied?}

Various possible mechanisms for supplying post-trial ART to participants have been proposed. ${ }^{6}$ These include:

(1) The investigators or their sponsors provide ART using research funds or other sources.

(2) The investigators or their sponsors pay for private insurance, contribute to a fund to pay for treating participants, or contribute the costs of treating participants to governmental programs.

(3) The trial participants are enrolled into further (treatment) trials.

(4) The participants are referred to government health services that supply ART, possibly with support and monitoring by researchers and/or sponsors. ${ }^{\text {? }}$

(5) Governments prioritize former research participants in their national AIDS plans.

(6) International aid is preferentially directed towards supplying ART to HIV/AIDS trial participants, or to countries that host trials. This may be governmental or non-governmental and bi-lateral or multilateral aid. ${ }^{8}$

(7) Some combination of the above mechanisms. For example, sponsors may agree to supply ART for a set period and then have national governments take over.

These mechanisms indicate the different parties who may be in a position to provide ART: the investigators, their sponsors, local or national governments, and national and international (governmental or nongovernmental) aid agencies. They also reflect practical difficulties with providing treatment. The development of antiretroviral drugs has transformed AIDS from an acute and deadly disease into a chronic condition. In the developed world, on average, a 20 year-old starting treatment

\footnotetext{
${ }^{6}$ See J. Ananworanich et al. Creation of a Drug Fund for Post-Clinical Trial Access to Antiretrovirals. Lancet 2004; 364: 101-102; E. Bass. Raising Hopes and Many Questions: Vaccine Trial Sponsors' New Approaches to Providing Antiretrovirals for Trial Volunteers. IAVI Report September 2003-January 2004; S. Berkley. Thorny Issues in the Ethics of AIDS Vaccine Trials. Lancet 2003; 362: 992; D.W. Fitzgerald et al. Provision of Treatment in HIV-1 Vaccine Trials in Developing Countries. Lancet 2003; 362: 993-4; Lo et al. op. cit. note 2; T. Tucker \& C. Slack. Not If but How? Caring for HIV-1 Vaccine Trial Participants in South Africa. Lancet 2003; 362: 995.

${ }^{7}$ Cf. A. Forbes. Moving Toward Assured Access to Treatment in Microbicide Trials. PLoS Med 2006; 3(7): e153.

${ }^{8}$ Examples include the President's Emergency Plan for AIDS Relief (PEPFAR), and the Global Fund To Fight AIDS, Tuberculosis and Malaria. This approach is mooted in Lo et al. op. cit. note 2.
}

can now expect to live another 43 years. ${ }^{9}$ Meeting an obligation to supply ART to trial participants is therefore a long-term undertaking. But in the developing countries in which many HIV/AIDS trials occur, not only may the medicines be unavailable, but the infrastructure through which to deliver them may be inadequate or non-existent. Providing access to ART therefore requires addressing shortages of clinics, monitoring equipment, and trained personnel, in addition to supplying the drugs themselves. Moreover, in some countries political and economic instability makes it hard to predict the future healthcare environment, which makes planning long-term care even more challenging. Treating participants who seroconvert in prevention trials is likely to exacerbate these concerns, since, as noted above, these people will generally not need treatment until a number of years after the trial. Unsurprisingly, therefore, many of the suggested mechanisms make use, in whole or in part, of government treatment programs.

\section{The disconnect in the literature}

The practical difficulties just noted are acknowledged in the literature that argues in favor of an obligation to provide ART to needy research participants. But in suggesting ways to solve the practical problems - that is, mechanisms for supplying ART - commentators often fail to respect the reasons they have given for providing treatment in the first place. Instead, they appear to believe that which parties ought to supply ART is simply determined by considerations of practicality. For example, in a recent article in $A I D S$ on prevention trials, Lo et al. argue that:

There are ethical as well as pragmatic reasons for this expectation of ART for seroconverters ... The more direct, frequent, and prolonged the researchparticipant interaction during an HIV prevention trial, the stronger the researcher's sense of responsibility to provide ART to participants who seroconvert during the study. Moreover participants in a clinical trial deserve reasonable benefits in return for their participation as a matter of reciprocal justice. ${ }^{10}$

Concerned that preferentially targeting participants would be unjust, Lo et al. propose that resources for ART be directed towards local or national programs, not just research participants. For example, they suggest that

\footnotetext{
${ }^{9}$ R. Hogg et al. Life Expectancy of Individuals on Combination Antiretroviral Therapy in High-income Countries: a Collaborative Analysis of 14 Cohort Studies. Lancet 2008; 372: 293-299.

${ }^{10}$ Lo et al. op. cit. note 2, p. 1229.
} 
'the US government should make PEPFAR funds available in all countries that host large prevention or clinical trials sponsored by US government agencies. ${ }^{11}$ But the quoted arguments suggest that research participants, in particular, deserve treatment: the relationship with a participant gives the researcher special duties to that participant, just as the physician-patient relationship gives a doctor special duties to her patients, not to someone else's. It is implausible that this relationship gives PEPFAR obligations to the participants' compatriots.

Similarly, with regard to HIV/AIDS treatment trials, the US National Institutes of Health's 2005 guidance states that 'the NIH expects investigators/contractors to address the provision of antiretroviral treatment to trial participants after their completion of the trial. ${ }^{12}$ It justifies this expectation by reference to the potentially harmful effects of discontinuing antiretroviral treatment. ${ }^{13}$ Now, the NIH is generally prohibited from providing treatment (its remit is restricted to research), so the suppliers of post-trial ART must be other parties. The guidance therefore recommends that investigators engage with other organizations working in the host country governmental and non-governmental - to secure on-going treatment for trial participants. ${ }^{14}$ This implicitly presumes that these other organizations have a responsibility to compensate the harm that the research would otherwise cause (through treatment discontinuation). But if I hurt someone, it is I, or at most those on whose behalf I am working, who ought to repair the damage, not innocent bystanders.

These examples illustrate the mistake of divorcing the justifications given for providing post-trial ART from the mechanisms proposed for supplying it. In the following sections I analyze the possible justifications for an obligation to supply post-trial ART to participants in HIV/AIDS treatment and prevention trials. For each justification I explain the moral principle (or principles) that underlie the justification, and show to whom the principle assigns duties and to whom the duty is owed (Table 1). This links the mechanisms that have been pro-

\footnotetext{
11 Ibid: 1230.

12 National Institutes of Health. 2005. Guidance for Addressing the Provision of Antiretroviral Treatment for Trial Participants Following their Completion of NIH-Funded HIV Antiretroviral Treatment Trials in Developing Countries. Available at: http://grants.nih.gov/grants/ guide/notice-files/NOT-OD-05-038.html [Accessed 2 July 2008].

${ }^{13}$ US Department of Health and Human Services. 2005. Questions and Answers Regarding Guidance for Addressing the Provision of Antiretroviral Treatment for Trial Participants Following their Completion of NIH-Funded HIV Antiretroviral Treatment Trials in Developing Countries. http://grants.nih.gov/grants/policy/antiretroviral/QandA. htm [Accessed 2 July 2008]: Answers 1 and 5.

${ }^{14}$ Ibid: Answers 9 and 10.
}

posed for supplying ART to trial participants to the reasons that have been given for doing so. For each justification I also note what evidence would need to be provided in order for that justification to require the provision of post-trial ART for a particular trial.

\section{B. JUSTIFICATIONS FOR SUPPLYING POST-TRIAL TREATMENT}

\section{Harm to participants}

There is widespread support for an obligation to compensate research participants for injuries that result from their participation in research. ${ }^{15}$ Arguments citing this obligation are perhaps the most common way to defend the claim that participants who seroconvert during vaccine trials deserve ART. For example, according to Udo Schüklenk and Richard Ashcroft at least some participants in vaccine trials will have a 'therapeutic misconception' that makes them think that they have received an effective vaccine. This will lead to them engaging in more risky behavior than they otherwise would have, and thereby increase the probability that they contract HIV. ${ }^{16}$ More recently, both microbicide and vaccine trials have been halted because infection rates were higher in the experimental than the control arms. In both cases some physiological effect of the experimental treatment might have made infection more likely, though whether this is the case and exactly what the mechanism of action might be is still unknown. ${ }^{17}$

Harm-based arguments have also been developed for treatment trials. Here, trial participation cannot be implicated in HIV-infection, since participants enter the trials in need of treatment. Instead, the arguments must show that taking people off treatment would cause a harm that should be restituted with ART. For example, it may be that putting someone on ART for a limited period of time

\footnotetext{
15 E.g., Council for International Organizations of Medical Sciences, World Health Organization. 2002. International Ethical Guidelines for Biomedical Research Involving Human Subjects. Geneva: CIOMS: Guideline 19.

${ }^{16}$ Schüklenk \& Ashcroft, op. cit. note 2, p. 168.

${ }^{17}$ P. Moszynski. Halt to Microbicide Trial Sets Back AIDS Research. $B M J$ 2007; 334. Subsequent analysis of the data from the STEP vaccine trials suggested that the group at increased risk of HIV infection was uncircumcised men with pre-existing immunity to adenovirus type 5 (Ad5), the virus used as the carrier for the HIV genes in the vaccine (National Institute of Allergy and Infectious Diseases, NIH. 2008 NIAID Will Not Move Forward With The Pave 100 HIV Vaccine Trial. Bethesda, MD: NIH. Available at: http://www.nih.gov/news/health/ jul2008/niaid-17.htm [Accessed 12 Jan 2009]).
} 
increases the probability that they will develop resistance to the antiretrovirals used; this may compromise future care. ${ }^{18}$ There is also some limited data that suggests that ART interruption may be implicated in an increased risk of cardiovascular disease. ${ }^{19}$

The likelihood that a participant's AIDS constitutes a research-related injury deserving compensation with ART will vary from trial to trial. Two key factors should be borne in mind. First, for almost every trial some of the people who have HIV/AIDS after the trial would have it independent of trial participation. (Indeed, given the state-of-the-art preventive methods normally used as the standard of care in vaccine trials, some participants who would otherwise have contracted HIV will not have done so.) Second, even for those people who are in need as a result of the trial, their need is likely to be only partly caused by trial participation. ${ }^{20}$ This is clearest in the case of post-trial access for treatment trials: even if, say, stopping antiretrovirals turned out to be harmful, participants already needed treatment before they enrolled. Strictly speaking, compensation is owed only to those people who need treatment because of the trial, and only to the extent that trial participation causes their need.

Suppose that the appropriate evidential standard were met for some group of trial participants. On whom would the obligation to supply ART fall? This depends on what underlies the obligation to compensate research-related injuries. First, it might be a requirement of reciprocity. Having borne the burden and taken the risks of research participation, it has been argued, research participants should not have to pay the costs of treatment when they are hurt. Instead, the costs should fall on those who

\footnotetext{
${ }^{18}$ G. Jourdain et al. Perinatal HIV Prevention Trial Group. Intrapartum Exposure to Nevirapine and Subsequent Maternal Responses to Nevirapine-based Antiretroviral Therapy. N Engl J Med 2004; 351: 229-240. See, also, S. Sungkanuparph et al. HIV-1 Genotype after Interruption of Non-nucleoside Reverse Transcriptase Inhibitor-based Antiretroviral Therapy and Virological Response after Resumption of the Same Regimen. Int J STD AIDS 2007; 18: 832-834.

19 A.N. Phillips et al. Interruption of Antiretroviral Therapy and Risk of Cardiovascular Disease in Persons with HIV-1 Infection: Exploratory Analyses from the SMART Trial. Antivir Ther 2008; 13: 177-187. ${ }^{20}$ For analysis of the data on the risk-taking behavior of participants in HIV-prevention trials see Slack et al. op. cit. note 4. They conclude that there is no good evidence that overall risk behavior of trial participants increases, and that it is possible to identify specific individuals who may engage in more risky behavior. Schüklenk and Ashcroft address the implications of this analysis in U. Schüklenk \& R. Ashscroft. HIV Vaccine Trials: Reconsidering the Therapeutic Misconception and the Question of What Constitutes Trial Related Injury. Dev World Bioeth 2007; 7(3): ii-iv.
}

benefit from the research. ${ }^{21}$ In Section 7 I consider in detail who has obligations of reciprocity and how far they extend.

Second, and more simply, it may be a case of restitution for causing harm: if one person harms another without her consent, then he should do what he can to return her to the condition she was in before the harm (or to provide some equivalent compensatory benefit). This obligation would fall specifically on the researchers and, where the harm resulted not from negligence but from trial design, the sponsors who employed them. Third parties would not have any obligation to supply treatment on this basis: I should not interfere with people fulfilling their special responsibilities, but neither do I have a duty to assist them.

In addition to the difficulties noted above in showing that participants' need for ART was caused by trial participation, there is another problem with applying this principle of restitution. Participants' consent to trial participation might be thought to constitute assuming the risks of accidental injury. And if someone has consented to be injured, the person who injures them does not owe restitution. Consequently, for this principle to justify post-trial treatment it would also have to be shown either that participants failed to give valid consent, or that the harm they experienced was the result of culpable negligence. The argument would be most plausible in the scenario suggested by Schüklenk and Ashcroft: the participants would not have had the mistaken beliefs (therapeutic misconception) that led to their risky behavior if they had properly understood the nature of the trial when they enrolled. It therefore indicates that something went wrong in the consent process, which implies that they did not consent to be harmed. In other cases, the argument would be much harder to make.

\section{Fiduciary relationships}

The role of physician is commonly thought to come with special responsibilities: physicians have duties to their patients that they do not have to others. Though researchers and physicians are distinct roles, medical researchers may also have special duties to their subjects. Such duties could include providing post-trial treatment.

The most detailed account of the special duties that researchers qua researchers have to their participants is Henry Richardson and Leah Belsky's account of

${ }^{21}$ E.g., J.F. Childress. Compensating Injured Research Subjects: I. The Moral Argument. Hastings Cent Rep, 1976; 6(6): 21-27. 
'ancillary care' obligations. ${ }^{22}$ Richardson and Belsky argue that these obligations arise from research participants' 'partial-entrustment' of their health to researchers. This partial-entrustment includes the disclosure of medical information, the tests that participants undergo, and the control they give researchers over their treatment. The scope of clinical of researchers' ancillary care obligations is determined by the nature of what is entrusted. Thus only those conditions that are being studied or are likely to be diagnosed by study procedures may merit additional care. The strength of the obligations is determined by the vulnerability of the participants, the gratitude researchers owe them for trial participation, and the intensity and duration of the relationship between researchers and participants. The greatest ancillary care obligations will therefore be owed to participants who desperately need health care that they cannot get elsewhere, who have been heavily burdened by trial participation, and who have developed a deep relationship with the researchers.

Supposing that Richardson and Belsky's account is correct, ${ }^{23}$ we can assess what characteristics a trial must have in order for researchers to acquire an ancillary care obligation to provide ART. In a recent article Richardson considers the hypothetical case of participants who seroconvert in a Phase-III HIV vaccine trial. ${ }^{24} \mathrm{He}$ argues that the participants are likely to be very vulnerable, that long-term interactions between participants and researchers imply a deep relationship, and that participants' HIV-status falls centrally within the scope of the study. Moreover, the cost of providing treatment for those who seroconvert, relative to the overall cost of the study, is likely to be low. Richardson suggests that this gives researchers a strong obligation to provide treatment. Presumably, the same factors would apply in treatment studies, too, though likely with different relative

${ }^{22}$ H.S. Richardson, L. Belsky. The Ancillary-care Responsibilities of Medical Researchers. Hastings Cent Rep 2004; 34: 25-33. They define ancillary care as 'that which goes beyond the requirements of scientific validity, safety, keeping promises, or rectifying injuries'. (p. 26). Though their theory was developed to help determine the obligations of researchers during a trial, it is clear from Richardson's later uses that it applies to post-trial obligations as well.

${ }^{23}$ Space does not permit critical assessment of the account here (some critical reflections can be found in N. Dickert et al. Ancillary-care Responsibilities in Observational Research: Two Cases, Two Issues. Lancet 2007; 369: 874-877). It is worth noting that the account incorporates a number of moral considerations - such as reciprocity and the duty of rescue - that I also consider separately in this paper. It is therefore unclear exactly what difference the relationship alone makes.

${ }^{24}$ H. S. Richardson. Gradations of Researchers' Obligation to Provide Ancillary Care for HIV/AIDS in Developing Countries. Am J Public Health 2007; 97: 1956-1961. costs, since everyone in a treatment study leaves the study needing ART. In this case, either the study budget would have to be large enough to support the cost of treatment comfortably, or the relationship between participants and researchers would have to be especially deep. Each of these factors varies from trial to trial. ${ }^{25}$

Were this burden of proof to be met, the resulting duty to supply ART would fall on the researchers, since it is they who are in the fiduciary relationship. However, as with research related injuries, sponsors will normally share responsibility. If I hire you to do something which will predictably lead to you acquiring costly responsibilities, a fair pay deal should include the costs of fulfilling these responsibilities. Thus, the sponsors of research may also be obligated to help fulfil duties arising from the researcher-participant relationship. Again, however, other third parties are not.

\section{Reciprocity}

The goal of medical research is to contribute to generalizable knowledge that can improve the health of human beings. Clinical trials are therefore primarily designed to answer scientific questions and only secondarily, if at all, to benefit trial participants. But since participants contribute to a benefit derived by others, it may be that they deserve something in return. This is the idea underlying duties of reciprocity, which a number of commentators cite as a justification for supplying ART to trial participants. ${ }^{26}$

Where individuals are owed reciprocal benefits, it is in virtue of the benefits they have provided to others; and what they are owed reflects their relative contribution. However, not everyone who is benefited owes her benefactor reciprocation. Suppose, for example, that you decide to spend an afternoon clearing an overgrown public path. This may benefit other people who use the path, but you cannot therefore demand that they pay you. By contrast, if I hire you to clear the path, then I owe you fair compensation for doing so; and if you are so hired and bring along a friend to assist you, you ought to share the payment you receive with her. What makes the difference in these last two cases is that the other people are voluntarily engaged in the enterprise that generates the

\footnotetext{
${ }^{25}$ For example, treatment trials sponsored by the National Institute of Allergy and Infectious Diseases at the US NIH vary in length from 12 weeks to 5 years (Seema Shah, personal communication).

${ }^{26}$ E.g. Lo et al., op. cit. note 2; Macklin, op.cit. note 2.
} 
benefit, either by commissioning it to be done or by taking part in doing it. ${ }^{27}$

In the case of research, the other parties engaged in the research enterprise are primarily the researchers and their sponsors. It is they who enlist participants into the study, and so it is plausible to think that it is they who ought to bear the cost of fair reciprocation for the participants' contribution. Though HIV/AIDS patients ${ }^{28}$ outside of the study may benefit from research on their condition, they are not voluntary partners in the research enterprise, and so need not reciprocate. (It might be that they should be grateful, since someone can have reason to be grateful to someone who benefits her without asking her first; but duties of gratitude are quite different from, and weaker than, duties of reciprocity. ${ }^{29}$ This implies that it would be unfair to demand that patients sacrifice their health care to return a benefit to trial participants, for example, by prioritizing trial participants for treatment at government health centers. ${ }^{30}$

Someone might object to this last conclusion in the following way: 'If a government sponsors research, or even if it just facilitates research by allowing trials to take place on its territory, the government is part of the research enterprise and so incurs duties to provide reciprocal benefits. But governments act on behalf of their citizens: legitimate governments express the will of their citizens and, by implication, the responsibilities that governments incur are the responsibilities of their citizens. Thus, people with HIV/AIDS may acquire duties of reciprocation to trial participants through the actions of their government.' However, even if the assumption about governments underlying this reasoning were correct (and, at best, it is an idealization of functioning democracies), it would still not follow that the responsibilities in question would be incurred just by HIV/AIDS patients. The actions of a legitimate government are on behalf of all of its citizens, and so the obligations belong to all its citizens, too - not just some subset of them. Government taxation and expenditure decisions are (at

\footnotetext{
${ }^{27}$ I leave this idea of voluntary engagement vague, since there is not space for proper analysis of the precise limits of reciprocal duties here. It should not affect my central point.

${ }^{28}$ Or people at risk for acquiring HIV/AIDS in the case of prevention studies.

${ }^{29}$ For a classic analysis of duties of gratitude see F. Berger. Gratitude. Ethics 1975; 85: 298-309. Space constraints and the relative weakness of duties of gratitude preclude my giving them serious consideration as an independent ground for an obligation to supply post-trial ART.

${ }^{30}$ See M. Merritt \& C. Grady. Reciprocity and Post-Trial Access for Participants in Antiretroviral Therapy Trials AIDS 2006; 20: 1791-1794 for a detailed analysis of whether and when it would be permissible to prioritize research participants for treatment, on the assumption that they are owed reciprocation by their compatriots.
}

least for the most part) constrained by considerations of distributive justice. Thus, if a national government does have an obligation to provide reciprocal benefits to trial participants, the cost of meeting that obligation should be met by spreading the burden fairly among all its citizens, not by penalizing HIV/AIDS patients. It is worth noting that this point applies to any obligations governments may acquire through sponsoring research: they are not normally at liberty to discharge these obligations at the expense of any particular group.

In order to show that ART is an appropriate return for participation in a particular HIV/AIDS trial a number of factors must be assessed. ${ }^{31}$ Most importantly, the amount of compensation that participants are owed will depend on the size of the contribution they make and the extent of the benefit (broadly understood) generated by the research. ${ }^{32}$ This will clearly vary between trials, but we can note two key points. First, whatever the final distribution of benefits, no one should be made worse off by fulfilling their duties of reciprocity. This follows from the point of reciprocity: it is an appropriate response to benefits received. ${ }^{33}$ Second, the amount might be more or less than the cost of providing ART: there is no reason to expect a priori that what someone is owed for her contribution to a particular piece of HIV/AIDS research will be equivalent to a lifetime of treatment.

\section{Beneficence and global justice}

International medical research takes place against a background of extreme economic disparities, which are reflected in massive differences in health and health care

\footnotetext{
${ }^{31}$ For reasons of space I omit some of these considerations. For example, I have not considered the difficult question of how to measure someone's contribution, nor the relative merits of different sorts of contribution.

${ }^{32}$ The relevant contribution for assessing desert is the ex ante contribution. This means that, in general, each participant in any particular trial will make the same sized contribution, and so deserve the same reward. In particular, in HIV prevention trials there is no difference in the contribution made to scientific knowledge by those who seroconvert and those who do not - each is equally important for assessing the effects of the study intervention (see Weijer and LeBlanc, op. cit. note 4, pp. 802-803 for a more complete argument to this effect). Note, however, that even if every participant deserves an equal benefit, it may still be appropriate to supply it by giving care just to those who are infected. The benefit supplied here would be the equivalent of giving each participant HIV-related health insurance. Finally, it is worth noting that if a trial enrolled different types of participants (e.g. healthy volunteers and patients) this might make a difference to their expected contributions and so to what they were owed as a matter of reciprocity. ${ }^{33}$ Cf. Merritt \& Grady, op. cit. note 30, p. 1792.
} 
between rich and poor. ${ }^{34}$ In most developing countries that host HIV/AIDS research, large numbers of people who need ART cannot get it. In contrast, in the developed world, ART is accessible to nearly everyone. Some people think that these differences affect what is owed to research participants in developing countries, either because it is unjust that they lack treatment when others have it, or simply because of the urgency of their need. ${ }^{35}$ In this section I consider how an obligation to provide ART to trial participants might be grounded in duties of justice or beneficence. Since the same critical considerations apply to both, I consider them together.

Duties of beneficence require us to act in ways that increase the welfare of others. There are two sources of these duties. First, everyone has a limited obligation to do something to improve other people's welfare, and some discretion about how to discharge this duty. This is the imperfect duty of beneficence. ${ }^{36}$ I could discharge my imperfect duty of beneficence by volunteering at the local homeless shelter, by campaigning to clean up the Chesapeake Bay, or by babysitting my neighbor's children. Second, everyone has a duty of rescue, which requires her to provide urgent assistance to others where she can do so at a (morally) insignificant cost to herself. ${ }^{37}$ For example, if I have training in first aid and I see someone collapse on the sidewalk, I have a duty to try to help, even if this makes me late for my 9 a.m. faculty meeting.

Providing trial participants with ART would clearly be a way in which someone could discharge their imperfect duty of beneficence. Moreover, it could be argued that the duty of rescue requires it, provided that its cost in a particular context was low enough, since without treatment people with AIDS will die. Furthermore, since both duties of beneficence are general duties they fall on

\footnotetext{
${ }^{34}$ United Nations Development Programme. 2007. Human Development Report 2007/2008. New York: Palgrave Macmillan: 219-384.

${ }^{35}$ E.g., UNAIDS/WHO. 2007. Ethical considerations in biomedical HIV prevention trials. Geneva: UNAIDS: 48. K. Shapiro \& S.R. Benatar. HIV Prevention Research and Global Inequality: Steps Towards Improved Standards of Care. J Med Ethics 2005; 31: 39-47; WHOUNAIDS Report. Treating People with Intercurrent Infection in HIV Prevention Trials: Report from a WHO/UNAIDS Consultation, Geneva July 17-18, 2003. AIDS 2004; 18: W4.

${ }^{36}$ Cf. I. Kant. [1797] 1996. The Metaphysics of Morals. In Practical philosophy / Immanuel Kant. Mary J. Gregor, trans \& ed.; general introduction by Allen Wood. Cambridge; New York: Cambridge University Press.

37 The duty of rescue is called a duty of 'specific beneficence' by Beauchamp and Childress, who give a more comprehensive list of the conditions under which it applies (T.L. Beauchamp \& J.F. Childress. 2001. Principles of Biomedical Ethics 5th edn. New York: Oxford University Press: 171).
}

everyone. ${ }^{38}$ Hence unlike, say, duties arising from the researcher-participant relationship, a duty of beneficence to supply ART could fall to governments or international bodies who are entirely independent of the research enterprise. Thus all the mechanisms that have been suggested for getting ART to trial participants would be legitimate ways to meet a duty of beneficence.

Theories of global justice are still young, and a number of fundamental problems regarding the scope and bearers of duties of justice have yet to be solved. ${ }^{39}$ Let us, however, suppose for the sake of argument that there is some duty to promote global justice possessed by individuals, and see what this would imply for the present case.

Like duties of beneficence, the duty to promote global justice is likely to be general - everyone will have it, not just those people who interact face to face with the global poor. Consequently, there is no reason to think that researchers working in the developing world have any greater duty to promote justice than people who are not, where those people could also make a difference. ${ }^{40}$ This implies, as with beneficence, that all the suggested mechanisms for supplying ART could be legitimate ways to fulfil a duty to promote justice.

The central problem with using either beneficence or justice to ground an obligation to supply ART to trial participants is that neither gives us reason to privilege trial participants over other equally needy people. Duties of beneficence and duties to rectify injustice are grounded in the unfortunate situation of the beneficiaries; they are not dependent on the beneficiaries participating in clinical trials. But the participants in clinical trials are not, by virtue of participation, worse off with regard to welfare or distributive justice than their compatriots; nor is treatment with antiretrovirals the only or most urgent need that people have. Hence in order to show, in some particular case, that justice or beneficence required prioritizing research participants, some additional reason would be needed.

\footnotetext{
${ }^{38}$ General duties are possessed by moral agents just in virtue of their agency, and owed to moral patients just in virtue of their moral status. ${ }^{39}$ One important debate concerns the extent to which considerations of justice apply internationally. Some argue that the requirements of distributive justice that apply to the basic structure of a nation state are much more stringent than those that apply to the global order (e.g. J. Rawls. 1999. The Law of Peoples; with 'The Idea of Public Reason Revisited'. Cambridge, Mass.: Harvard University Press). Others think that justice applies globally just as much as it applies nationally (e.g. C.R. Beitz. 1979. Political Theory and International Relations. Princeton, NJ: Princeton University Press).

${ }^{40}$ Indeed, if they are conducting research that responds to the health needs of poor communities, researchers may be already playing their part in correcting injustice (cf. Weijer \& LeBlanc, op. cit. note 4, p. 804)
} 
Table 1. Possible Justifications for providing post-trial treatment

\begin{tabular}{|c|c|c|c|}
\hline Justification & Duty bearer & Duty owed to & Benefits owed \\
\hline $\begin{array}{l}\text { Harm to } \\
\text { participants }\end{array}$ & $\begin{array}{l}\text { The responsible causes of injuries } \\
\text { i.e. researchers, sponsors }\end{array}$ & $\begin{array}{l}\text { Only those injured by research procedures } \\
\text { i.e. injured participants }\end{array}$ & Compensation proportional to harm \\
\hline $\begin{array}{l}\text { Fiduciary } \\
\text { relationship }\end{array}$ & $\begin{array}{l}\text { Trustees in the relationship } \\
\text { i.e. researchers, sponsors }\end{array}$ & $\begin{array}{l}\text { Beneficiaries in the relationship } \\
\text { i.e. participants }\end{array}$ & $\begin{array}{l}\text { Depends on vulnerability of participants, } \\
\text { gratitude owed, and depth of relationship }\end{array}$ \\
\hline Reciprocity & $\begin{array}{l}\text { Beneficiaries who facilitated the research } \\
\text { i.e. researchers, sponsors, governments } \\
\text { who facilitate research }\end{array}$ & $\begin{array}{l}\text { Contributors to research } \\
\text { i.e. participants, researchers, sponsors, } \\
\text { governments who facilitate research }\end{array}$ & $\begin{array}{l}\text { A fair share of the benefits generated by } \\
\text { research }\end{array}$ \\
\hline Duty of rescue & All those who can help & People in urgent need & Provision of vital assistance if at low cost \\
\hline $\begin{array}{l}\text { Imperfect duty } \\
\text { of beneficence }\end{array}$ & All those who can help & People in need & Contribution to increase in total welfare \\
\hline Global justice & All those who can help & People in unjust situations & Contribution to making the world more just \\
\hline
\end{tabular}

One possible reason would be that helping research participants would contribute more to overall justice or well-being than other uses of the same resources. This could be the case if it were more efficient to treat them than other people. For example, suppose a research project built treatment facilities and trained personnel to carry out its HIV/AIDS treatment study in a rural community. Though the community would not have been the preferred location for a treatment center if the government were planning from scratch, it is much cheaper to take over an existing facility than to build a new one. Moreover, if the same treatment center were to be used, it might also make sense for it to serve much the same population. In these circumstances it could be eminently reasonable for the program to continue to treat the trial participants: this would enable the government to treat more people at the same cost. Arguably, this is a better way for the government to discharge its duties than less efficient delivery of health care.

Thus, if insisting on the provision of ART to HIV/ AIDS trial participants makes the world a better place, either by improving people's welfare or making it more just, this might justify prioritizing them. If it does not, but merely shifts resources around, then it cannot be a requirement of beneficence or justice. In each case, unless we have good reason to think that the former is true, we should conclude that neither duties of beneficence nor requirements of distributive justice imply that HIV/AIDS research participants, in particular, should be targeted. ${ }^{41}$

\footnotetext{
${ }^{41}$ Similar considerations would apply if the justification cited historical instead of present injustices. For example, rich countries might owe poorer countries reparations for the harms of colonialism. Again, however, these reparations would not be owed to research participants in particular.
}

\section{IMPLICATIONS OF THE ANALYSIS}

\section{Key lessons about the provision of ART}

Table 1 summarizes my conclusions regarding connections between the suggested justifications for an obligation to provide post-trial ART and the bearers of the obligations. In addition to my conclusions regarding particular justifications, the analysis allows us to draw several useful general conclusions.

First, it indicates that, in general, justifications that would place the onus on government programs - such as beneficence and justice - imply a similar obligation to people outside of medical research. On the other hand, justifications that would imply an obligation owed to research participants in particular - like compensation for harm or the research-participant relationship - tend to be those that obligate just the researchers and their sponsors.

Second, we can assess what should happen to the global amount and distribution of resources to treat HIV/ AIDS. Considerations of beneficence and distributive justice require that we look at all the total consequences of providing treatment to trial participants. They will not justify making people worse off or the world less just, on aggregate, in order to benefit trial participants. If trial participants have incurred substantial research related injuries, if the researcher-participant relationship is of sufficient intensity, or if the wider benefits of the research are great enough, then researchers and sponsors may have a duty to provide post-trial treatment to their participants. But they may not do this by diverting treatment that would otherwise have gone to different patients; instead, they must contribute resources for treatment themselves. Even if governments with HIV/AIDS treatment programs incur special obligations to trial 
participants, they may not meet these obligations by penalizing citizens with HIV/AIDS, but must spread the cost fairly, which will increase the total resources they direct towards ART. ${ }^{42}$ A key lesson, then, is that the fulfillment of any of these obligations should maintain or increase the total global provision of ART.

Third, even if they justify duties of care to trial participants, the justifications considered do not all imply that ART, in particular, should be provided. In the case of HIV-infection as a research related injury, ART seems like an appropriate response, since this is the only way to approximate repairing the damage done. But in the case of the researcher-participant relationship, a particular trial might involve only brief interactions over a short period of time, which would imply only limited ancillary care obligations. Likewise, the extent of duties of reciprocation depends on the size of the benefit generated by the particular trial, which will vary. Thus how much is owed will differ from trial to trial. In some cases it may be that ART need not be given at all in order to discharge the duties; in other cases, ART may be appropriate, but for a limited period of time. It is not possible to determine exactly what is owed without looking at the details of particular research projects.

This last point brings me to an important reminder: any argument to show that trial participants should be

\footnotetext{
42 Whatever the reason for the obligations being acquired, the cost of doing so should be shared fairly among the citizens. Except in the case where a fair share would mean burdening only those citizens with HIV/AIDS, this implies that whatever the costs imposed on citizens with HIV/AIDS, they would be outweighed by the increase in provision of ART.
}

given post-trial ART must show that for that particular trial the appropriate burden of proof has been met. For each putative justification, I have indicated what would have to be shown for an obligation to result. However, I have not assessed the likelihood that any particular trial meets the burden of proof.

\section{Conclusion}

It is not enough to decide that participants in HIV/AIDS trials ought to get treatment after the trial ends and then look for ways to direct resources to them. The reasons why trial participants should get ART affect who has the duty to provide it. We should not burden governments with the obligations of sponsors, nor researchers with the obligations of the international community. And we should not deprive a group of treatment because their need is less salient than that of research participants. Insisting otherwise may lead to people being wrongfully deprived of treatment.

\section{Acknowledgements}

I would like to thank Christine Grady, Reidar Lie, Seema Shah, Cathy Slack, and two anonymous reviewers for Bioethics for helpful comments on previous drafts of this paper.

Joseph Millum holds a joint appointment as a Research Fellow at the Clinical Center Department of Bioethics and the Fogarty International Center at the National Institutes of Health. His research focuses on the ethics of parenthood and international research ethics. 